\title{
EDUCAÇÃO DO CAMPO, DESIGUALDADES SOCIAIS E EDUCACIONAIS
}

\author{
MARIA ANTÔNIA DE SoUZA*
}

\begin{abstract}
RESUMO: O objetivo deste texto é caracterizar a gênese da prática e concepção da educação do campo, atentando para a concentração da terra e da propriedade como elementos estruturais geradores de desigualdade social. É propósito, ainda, destacar as principais conquistas efetivadas de 1990 até 2012 no âmbito da educação do campo e pontuar conflitos judiciais em torno do direito à educação superior entre os povos do campo. As reflexões apresentadas neste artigo são oriundas de pesquisa bibliográfica e documental, bem como de estudos empíricos realizados no período de 2002 a 2012. Tem-se como pressuposto central que a educação do campo é fruto de experiência coletiva construída pelos movimentos e organizações de trabalhadores do campo.
\end{abstract}

Palavras-chave: Educação do campo. Desigualdade. Políticas educacionais.

\section{RURAL EDUCATION, EDUCATIONAL AND SOCIAL INEQUALITIES}

ABSTRACT: The objective of this text is to characterize the genesis of rural education's practice and conception, noting the land concentration and the property concentration as structural elements generating social inequality. It's purpose, is also, to highlight the main achievements that took place from 1990 to 2012 within the rural education, and point out legal disputes regarding the right to higher education among the people of the field. The reflections presented in this article are from bibliographical and documental researches, as well as empirical studies conducted from 2002 to 2012. We make the core assumption that rural education is the result of collective experience built by movements and organizations of rural workers.

Key words: Rural education. Inequality. Educational policies.

Doutora em Educação e professora do Programa de Pós-Graduação em Educação da Universidade Tuiutí do Paraná (UTP) e da Universidade Estadual de Ponta Grossa (UEPG). E-mail: masouza@uol.com.br 


\title{
ÉDUCATION EN ZONE RURALE, INÉGALITÉS SOCIALES \\ ET ÉDUCATIONNELLES
}

\begin{abstract}
RÉSUMÉ: L'objectif de cette étude est de caractériser la genèse de la pratique et de la conception de l'éducation en zones rurales, en faisant attention à la concentration des terres et de la proprieté comme des éléments structuraux qui engendrent l'inégalité sociale. C'est, aussi, dans le but de mettre en évidence les principaux acquis réalisés de 1990 jusqu'à 2012 dans le domaine de l'éducation en zones rurales et de souligner des conflits judiciaires autour du droit à l'éducation supérieure concernant les peuples des zones rurales. Les réflexions présentées dans cette étude sont le résultat d'une recherche bibliographique et documentaire, ainsi que d'études empiriques accomplies de 2002 à 2012. On a la prémisse centrale que l'éducation en zones rurales est le résultat de l' expérience collective construite par les mouvements et les organisations de travailleurs agricoles.
\end{abstract}

Mots-clés: Éducation en zones rurales. Inégalité. Politique éducative.

\section{Introdução}

$\mathrm{E}$ ste texto traz reflexões sobre a educação do campo em desenvolvimento no Brasil a partir de 1990. A intenção é identificar aspectos dessa prática e concepção educacional que valoriza a formação humana dos povos do campo. Em outros textos, discutimos a trajetória e a experiência da educação rural no país e suas diferenças político-pedagógicas com relação à educação do campo. Sem ignorar a secular trajetória da educação rural e as desigualdades e fragilidades geradas em seu contexto, o propósito agora é apontar os impactos e conquistas de uma prática social que valoriza cultura, identidade, trabalho e formação humana.

As seguintes interrogações norteiam este artigo: Quais são as marcas da gênese da prática e concepção da educação do campo? Quais são as conquistas da educação do campo nos anos de 1990? Nos últimos 10 anos, desde a aprovação das Diretrizes Operacionais para a Educação Básica nas Escolas do Campo (2002), quais práticas coletivas e resultados foram alcançados entre os povos do campo no que tange à política educacional?

Temos como pressuposto central que os condicionantes estruturais históricos da sociedade brasileira - concentração da terra e da riqueza; cultura patrimonialista com fortes marcas na sociedade civil e no Estado; ideologia conservadora no que se refere ao trato da questão social pelos poderes legislativo e judiciário, especialmente - são responsáveis pelas contradições que conformam o quadro atual de desigualdades sociais. Dados publicados pelo Instituto de Pesquisa Econômica Aplicada (Ipea, 2010) revelam que a diminuição da pobreza é significativa no país, mas que a redução da desigualdade ainda é lenta. No âmbito educacional, as oportunidades 
não são iguais, embora o artigo $5^{\circ}$ da Constituição da República Federativa do Brasil expresse que "todos são iguais perante a lei". Não é o que se constata em vários setores da vida social e, sobretudo, na política de educação superior, cuja abertura para diversas categorias sociais e para os beneficiários da reforma agrária tem sido motivo de controvérsias judiciais.

Do ponto de vista metodológico, os dados apresentados neste artigo são oriundos das nossas pesquisas do período de 2002 a 2012 sobre escolas públicas localizadas no campo, educação e movimentos sociais do campo, e decisões do poder judiciário sobre os cursos superiores para beneficiários da reforma agrária. Nessas investigações de natureza qualitativa e com o uso das técnicas de entrevista, análise de documentos e conteúdos bibliográficos foi possível constatar três características importantes ao debate da educação do campo, a saber:

1) A presença da ideologia da educação rural juntamente com a ideologia da educação do campo. Ou seja, pelas entrevistas realizadas com 12\% dos professores que trabalham em escolas públicas do campo, no estado do Paraná, e pelas observações diretas em dez escolas, nos últimos dois anos, verifica-se uma rotina escolar marcada pelo uso do livro didático, conhecimento parcial ou inexistente das diretrizes nacionais da educação do campo, inúmeras dificuldades de acesso à formação continuada por parte dos professores, além das fragilidades teóricas e principiológicas dos planos municipais de educação e dos projetos político-pedagógicos, no que diz respeito à valorização da identidade, cultura e trabalho do campo. Entretanto, é possível identificar que, em localidades onde os movimentos e organizações populares do campo são atuantes, os professores reorganizam projetos político-pedagógicos, interessam-se pelo aprofundamento das características contraditórias da sociedade brasileira e das ruralidades.

2) A ampliação dos estudos sobre a relação entre educação e movimentos sociais, em especial sobre as diversas experiências coletivas da educação do campo. Identificamos, até fevereiro de 2011, 250 pesquisas de pós-graduação em Educação - mestrado e doutorado. A partir da análise do conteúdo de 102 pesquisas, verificamos que, até final dos anos de 1990, elas tratavam incisivamente da gênese do Movimento dos Trabalhadores Rurais Sem Terra (MST), educação no MST e processos de conscientização política. A partir de 2000, as pesquisas dão ênfase às experiências do Programa Nacional de Educação na Reforma Agrária (Pronera), tais como formação de professores, práticas educativas, educação e trabalho, políticas educacionais. A partir de 2005 evidencia-se o conceito de educação do campo em dezenas de investigações educacionais, revelando as relações entre capital e trabalho, trabalho e educação, 
articulações entre sociedade civil e sociedade política, construção de esfera pública na definição das políticas educacionais, formação de professores e educação superior.

3) O debate das desigualdades educacionais e do direito à educação adentra o Judiciário brasileiro, por meio das ações civis públicas propostas por membros do Ministério Público Federal e associações de categorias, tais como a dos agrônomos, contra os cursos superiores para os beneficiários da reforma agrária. Análise documental de três ${ }^{1}$ ações civis públicas no país revelam as contradições que marcam o Judiciário brasileiro, uma vez que os princípios constitucionais da igualdade, legalidade e proporcionalidade são utilizados como fundamentos em ações e respostas favoráveis e também nas contrárias a tais cursos superiores. Constata-se maior conservadorismo entre os membros do Ministério Público Federal (MPF), em dois dos casos analisados, do que entre os membros do Poder Judiciário. Como escreveu Molina (2008, p. 26), a justiciabilidade do direito à educação tem sido força importante para politizar o debate da educação. Entretanto, a própria autora afirma que “(...) não podemos ter a ilusão de que, submetendo essa demanda ao Poder Judiciário, o direito à educação aos sujeitos do campo estará garantido".

A concepção de educação do campo presente neste artigo é a de que se trata de uma construção coletiva, que tem início com o questionamento das práticas desenvolvidas nas escolas localizadas nos assentamentos da reforma agrária, e é ampliada para o âmbito das políticas, em especial as lutas pelo acesso à educação básica e superior, contra o fechamento de escolas, pela formação dos professores e infraestrutura adequada nas escolas. É uma construção coletiva que surge fora dos muros escolares, porém questionando a lógica educacional tradicional, os direitos sociais, a cultura do fazer política educacional e o "histórico padrão segregador de conhecimentos", nos termos de Arroyo (2012, p. 233). Como prática efetivada fora da escola, ela coloca em destaque vários problemas, a exemplo dos processos sociais vivenciados pelos trabalhadores que, historicamente, resistem nas terras e águas; participam de conflitos por terra; enfrentam o avanço do agronegócio e a dificuldade na geração de emprego e nas condições sustentáveis de vida.

Dessa forma, a educação do campo como construção coletiva adentra a instituição escola e amplia as formas de lutas fora da escola por formação humana e pela efetivação de processos de conscientização política. Como afirma Arroyo (2012, p. 233), "As resistências à opressão e as lutas pela libertação são múltiplas e se reforçam, porque há consciência de que os processos históricos de opressão são múltiplos e se reforçam".

Neste artigo há ênfase, num primeiro momento, à gênese da prática e concepção da educação do campo, atentando para a concentração da terra e da propriedade 
como elementos estruturais geradores de desigualdade. Posteriormente, são expostas as principais conquistas da educação do campo nos anos de 1990. Ao final, são destacados os últimos dez anos, indicando as possibilidades de acesso à educação por parte da população do campo.

\section{Gênese da educação do campo: entre condicionantes históricos e lutas pela superação das contradições}

A concentração da propriedade é a prova da desigualdade entre os homens, tal qual apresenta Rousseau em seu discurso sobre a origem e os fundamentos da desigualdade entre os homens. Para ele,

(...) desde o momento em que um homem teve necessidade do auxílio de outro, desde que se apercebeu de que seria útil a um só indivíduo contar com provisões para dois, desapareceu a igualdade, a propriedade se introduziu, o trabalho se tornou necessário e vastas florestas se transformaram em campos aprazíveis, que foi preciso regar com o suor dos homens e, nos quais, viu-se logo a escravidão e a miséria germinarem e crescerem com as colheitas. (Rousseau, 1997, p. 94)

No Brasil, Stefaniak (2003) relembra que o território era povoado por indígenas, que mantinham a propriedade coletiva da terra, até a chegada dos colonizadores. Do ponto de vista jurídico, o regime de sesmarias, que caracterizou a apropriação das terras brasileiras, "consistia na concessão de áreas de terras denominadas capitanias hereditárias para os chamados donatários, que deveriam assegurar a posterior fundação de vilas e povoados, nas quais deveriam criar meios para manter o poder político e militar" (p. 52-53). Esse regime era regulado pelas Ordenações do Reino, que determinaram a origem dominial das terras brasileiras. A partir de 1822, teve início o sistema de posse.

A Lei n. 601/1850 ficou conhecida como Lei de Terras, sob a égide da Carta Constitucional de 1824. De acordo com a Lei, a aquisição da propriedade ocorreria pela compra mediada pelo mercado. As terras não pertencentes a particulares passariam a ser de domínio do Império e seriam denominadas "devolutas". As pessoas que tinham posse de áreas devolutas poderiam tornar-se proprietárias mediante um pagamento à Coroa. Deu-se margem para o fenômeno da grilagem de terras (Stefaniak, 2003). A Constituição de 1824 estabeleceu o direito absoluto à propriedade, em seu artigo 170. Foram 300 anos de regime sesmarial que deram origem ao Brasil latifundiário e difusor da ideologia de que indígenas e negros são povos inferiores. Até os dias de hoje, a concentração da terra e da propriedade tem gerado infinitos conflitos no país e tensões político-ideológicas que dificultam a valorização do trabalho do agricultor, do pescador, do assentado, do ribeirinho, das comunidades quilombolas, dos 
povos das florestas e de tantas outras categorias que dedicam a sua vida à produção de alimentos para consumo interno. Como afirma Arroyo (2012, p. 231), as inferiorizações raciais operam na formação política como legitimadoras de poder. Porém, “(...) as reações políticas dos movimentos sociais indígenas, negros e quilombolas têm sentido especial, por afirmarem identidades positivas e desconstruírem hierarquias e lugares e papéis sociais inferiorizantes e segregadores".

Os conflitos por terras marcam a história brasileira, em particular o século $\mathrm{XX}$, que teve a organização de movimentos, como as Ligas Camponesas, Movimento dos Trabalhadores Rurais Sem Terra (MST), Movimento dos Atingidos por Barragens; Movimento de Mulheres Camponesas; a Via Campesina, o Movimento Quilombola, entre tantos outros. Mediadores desses movimentos foram as Comunidades Eclesiais de Base, a Comissão Pastoral da Terra e, nos últimos anos, os pesquisadores das universidades públicas têm sido mediadores, parceiros e assessores fundamentais ao avanço do debate e das políticas sociais.

Importante destacar legislações que dão ênfase ao trabalho do pequeno agricultor, como é o caso da Lei n. 11.326, de 24 de julho de 2006, que estabelece diretrizes para a formulação da Política Nacional da Agricultura Familiar e Empreendimentos Familiares Rurais, e da Lei n. 11.947, de 16 de junho de 2009, que dispõe sobre o atendimento da alimentação escolar e, em seu artigo $2^{\circ}$, Inciso V, versa sobre:

O apoio ao desenvolvimento sustentável e incentivos para aquisição de gêneros alimentícios diversificados, produzidos em âmbito local e preferencialmente pela agricultura familiar e pelos empreendedores familiares rurais, priorizando as comunidades tradicionais indígenas e de remanescentes de quilombos.

São conquistas no âmbito da legislação que abrem espaço para políticas de valorização do trabalho dos povos do campo. São frutos das inúmeras lutas históricas dos movimentos sociais e das denúncias feitas por pesquisas de viabilidade econômica e social nos assentamentos da reforma agrária.

Entretanto, a concentração da propriedade persiste. Informações do Núcleo de Estudos em Reforma Agrária (Nera), da Universidade Estadual Paulista Julio de Mesquita Filho (Unesp/Presidente Prudente), demonstram que, em 2003, o Brasil possuía 33.104 propriedades com tamanho igual ou acima de 2 mil hectares, consideradas grandes propriedades. Aquelas com menos de 200 hectares somavam 3.971.255 imóveis. Ao lado da concentração da terra no país, da dificuldade de gerar empregos e de melhorar as condições de vida dos povos do campo, há uma ideologia que afirma que o Brasil é urbano, em contraponto a estudos que afirmam que as características do país estão fundadas em relações culturais, econômicas e sociais rurais, a exemplo de Veiga (2003) e Verde (2004). 
No cenário de concentração da propriedade, somado à migração campo-cidade desencadeada pelos processos de expropriação no campo e de atração para o trabalho nas cidades, emerge o fenômeno político de fechamento e nucleação de escolas. A partir dos anos de 1980, muitas escolas públicas rurais isoladas e unidocentes (estaduais e municipais) foram fechadas sob a alegação de que o número de alunos não era suficiente para a manutenção das turmas e classes escolares.

Esse fenômeno surgiu nos anos de 1980 e ganhou maior força na última década. O MST (2011), ao lançar a Campanha Nacional Contra o Fechamento de Escolas, destacou que mais de 24 mil escolas no campo brasileiro foram fechadas no meio rural desde 2002 e que dados do Censo Escolar do mesmo ano identificaram 107.432. Porém, em 2009, esse número reduziu para 83.036, indicando o fechamento de 24.396 escolas, das quais 22.179 eram municipais.

A referida Campanha coloca em destaque um fator estrutural da sociedade brasileira, ou seja: a existência de dois projetos para o Brasil, sendo um do agronegócio e outro da classe trabalhadora. $\mathrm{O}$ fechamento das escolas atenderia à ideologia de que o campo está "esvaziado" e de que as pessoas que trabalham a terra não necessitam de estudos. Souza (2012) registra a ideologia que orienta o Ministério Público Federal de Goiás, que questiona a legalidade e adequação do curso de Direito para assentados, alegando que o lugar de atuação do profissional de Direito é a cidade; e a ideologia da Associação dos Engenheiros Agrônomos do Estado de Sergipe, que refutou o curso de Agronomia para assentados, do Pronera, e alegou que o adequado seria a oferta de curso técnico-profissional para eles. Portanto, registram-se as ideologias e desigualdades enraizadas historicamente numa sociedade em que a propriedade da terra, durante muito tempo, se confundiu com a propriedade do próprio Estado.

Diante do que foi exposto, constatamos que a gênese da educação do campo está atrelada à luta pelo reconhecimento da existência dos povos do campo em sua diversidade e pela efetivação dos direitos sociais, bem como pela superação da ideia de que o campo é o lugar do atraso. Essa luta teve início, no âmbito pedagógico, com as experiências do MST, cuja trajetória pode ser encontrada no Dossiê MST Escola, publicado em 2005.

Está em construção no país um movimento nacional da educação do campo (Munarim, 2008). Esse movimento tem a participação de importantes sujeitos coletivos, a exemplo do MST; do Movimento Docente com amplas lutas pela educação pública, gratuita, de qualidade e para todos; Movimento dos Pequenos Agricultores; sindicatos de trabalhadores rurais e federações vinculadas à Confederação dos Trabalhadores da Agricultura; Rede de Educação do Semiárido brasileiro; Comissão Pastoral da Terra, entre diversas organizações locais. Trata-se de 
um movimento nacional constituído de organizações sólidas, como diz o referido autor. Dessa forma, "A educação do Campo, a par de se constituir um movimento em si, se constitui num conteúdo, numa agenda comum de sujeitos sociais diversos" (Munarim, op. cit., p. 5).

As experiências e lutas da educação do campo colocam em evidência a histórica desigualdade educacional da sociedade brasileira, em que os trabalhadores são os que possuem menor escolaridade. Também, dão ênfase aos diversos problemas estruturais e conjunturais, tais como concentração da terra e dificuldades materiais para a efetivação da produção agrícola e geração de empregos nas pequenas propriedades e nos assentamentos de reforma agrária, entre tantas outras.

Sobre as desigualdades educacionais, é importante retomar informações presentes no Panorama da Educação do Campo (Brasil, 2007), a exemplo do que segue: média de anos da população com 15 anos de idade ou mais: na região Sul do Brasil chega a cinco anos, ao passo que no Nordeste essa média é de 3,1 anos de estudos. Em 2004, a média de anos de estudo da população brasileira com 15 anos ou mais era de 6,8, sendo na área urbana de 7,3 e na área rural 4,0.

A distorção idade-série também é expressiva entre os estudantes do campo. $41,4 \%$ das crianças que estudam nos anos iniciais possuem distorção idade-série; $56 \%$ das que estudam de $5^{\text {a a }} 8^{2}$ também e $59 \%$ dos que estão no ensino médio também possuem distorção. Vários fatores explicam essa realidade: distância de casa à escola; inexistência de escola; migração de um município para outro, muitas vezes resultando em perda do ano letivo; repetência; calendário escolar em divergência com as necessidades de trabalho na agricultura, entre outros. Na maioria das situações estão em evidência o descaso e a falta de responsabilidade política e social dos entes federados.

Em torno de 50\% das classes são multisseriadas nas escolas localizadas no campo e, em muitas delas, o professor acumula funções de coordenador pedagógico e gestor. Por conta disso, ele tem pouca oportunidade de participar de grupos de estudos e demais processos de formação continuada. O Programa Escola Ativa, implantado em 1997 por meio de convênio do Ministério da Educação com o Banco Mundial, tem sido uma possibilidade para a inserção desses professores no debate da educação do campo. Esse programa efetiva-se com parcerias entre governos dos estados, governo federal, municípios e universidades. Inúmeras críticas são tecidas a esse programa nas pesquisas educacionais. Algumas delas são apresentadas por Marsiglia e Martins (2010, p. 7), que analisaram as orientações pedagógicas para a formação de educadoras e educadores. Para elas, "Em diversos trechos valoriza-se a ação do professor, a educação escolar e os conteúdos curriculares. Mas, em contrapartida, são trazidas justificativas e fundamentações que contradizem essas afirmações 
ou as apresentam de forma incompleta". Demonstram a presença do ecletismo e de contradições nas orientações pedagógicas. Salientam que "o material não deixa claro em qual referencial teórico está se fundamentando para a concepção de gestão democrática apresentada e seus respectivos órgãos" (p. 9). Trata-se de um programa que, como concluem as autoras, traz avanços para as políticas públicas para a educação do campo, porém traz também “(...) limitações históricas de perpetuação da burguesia e os desvios de uma verdadeira educação emancipadora decorrentes do discurso hegemônico da classe dominante" (p. 13).

Em síntese, são diversas as desigualdades presentes no campo e nas cidades brasileiras. Contudo, como escreve Wanderley (2000, p. 102), no campo elas são gritantes e englobam diversas categorias:

Sem sombras de dúvida, a realidade no campo continua sendo uma questão historicamente recorrente, predominando aí uma situação das mais injustas e desiguais. Ela recobre necessariamente as três realidades - indígena, negra e feminina - já que entre os segmentos sociais rurais são encontrados parcelas populacionais proporcionalmente mais oprimidas, exploradas e excluídas.

É na tentativa de superar desigualdades e ampliar a discussão de um projeto de país que as práticas educativas coletivas ficaram conhecidas como educação do campo, em oposição à educação rural. Esta se vincula às políticas oficiais historicamente organizadas no Brasil e que sempre tiveram a ideologia de educar para superar o atraso, e para fixar o homem no campo, sem indagar as origens contraditórias das desigualdades verificadas no meio rural. A educação do campo é uma frente de luta e de enfrentamentos com o Estado, ao mesmo tempo em que se encontra ao lado do Estado e dentro das instâncias governamentais em inúmeros projetos e programas. Trata-se de uma esfera pública marcada pela contradição e pela luta contínua, em que sociedade civil e sociedade política se encontram para a efetivação de direitos sociais. É uma esfera pública tensa, em que o dissenso é a mola propulsora das tensões ideológicas, políticas e jurídicas, também necessárias para o avanço da democracia.

\section{As principais conquistas da educação do campo nos anos de 1990}

As conquistas da década de 1990 podem ser agrupadas em três frentes. A primeira diz respeito ao fortalecimento do caráter coletivo da prática educativa, a exemplo das experiências do MST, dos indígenas, comunidades quilombolas, ribeirinhos, jovens e adultos, para citar alguns. São sujeitos de direitos - coletivos - que, aos poucos, modificam a história, ao buscar o reconhecimento territorial e a diversidade sociocultural. 
Muitos desses coletivos educativos deram origem a organizações estaduais e nacionais, como é o caso da Articulação Nacional da Educação do Campo e das Articulações Estaduais. Encontros nacionais, tais como o I Encontro Nacional de Educadoras e Educadores da Reforma Agrária, em 1997, e posteriormente a I Conferência por uma Educação Básica do Campo em 1998, reuniram diversas categorias de trabalhadores do campo. Esses coletivos deram origem a espaços públicos que agregaram forças (entidades sociais, universidades, movimentos sociais, organismos nacionais e internacionais) importantes para definição das políticas educacionais e das parcerias entre governos, universidades, movimentos e organizações populares.

Importante relacionar essa primeira frente de conquistas da educação do campo com o que Munarim $(2008,2011)$ denomina de dimensão política, marcada por "ações regulares coordenadas por políticas públicas por parte dos sujeitos sociais coletivos (...)” (Munarim, 2011, p. 22). Essa dimensão política tem como essência o espaço público em que se reúnem os diversos movimentos e se articulam as suas ações, lutas e proposições.

A segunda frente refere-se à consolidação da dimensão pedagógica voltada para a formação humana, ou o que Munarim $(2008,2011)$ denomina de dimensão pedagógica. Nela são materializados "projetos político-pedagógicos inovadores em instituições tradicionais, que vão desde escolas regulares de educação básica até universidades, passando pela educação de jovens e adultos fora dessas instituições (...)" (Munarim, 2011, p. 22).

Nos anos de 1990 a dimensão pedagógica centrava-se nas produções bibliográficas e práticas educativas do MST voltadas aos assentamentos e acampamentos da reforma agrária, conforme escrevem Vendramini (1992), Caldart (1997) e Souza (2006).

Busca-se construir uma prática educativa coletiva que se desdobra em produção do conhecimento e valorização da postura crítica na prática e gestão escolar; na análise dos conteúdos e metodologias de ensino; no planejamento de formas de avaliação, a exemplo dos ciclos de formação empreendidos nas escolas itinerantes. Importante notar que, no âmbito da legislação, a LDB n. 9.394/96 possibilita que os gestores das escolas do campo definam calendário e processo pedagógicos próprios, embora somente em 2008 tenha sido normatizada a obrigatoriedade do ensino da história e cultura afro-brasileira e indígena nos ensinos fundamental e médio. São conquistas que derivam das inúmeras lutas dos trabalhadores.

A terceira frente, consequentemente, é o reconhecimento da existência dos povos do campo e da sua diversidade. O grande impacto em relação aos povos do campo, nos anos de 1990, adveio dos resultados do I Censo da Reforma Agrária do Brasil (1997). Por esse censo, dos 161.556 beneficiários da reforma agrária indagados, 46.577 eram analfabetos; 15.600 possuíam alfabetização incompleta; 66.796 
possuíam alfabetização completa até a quarta série; 16.490 tinham entre a quinta e a oitava séries concluídas; 3.720 tinham o ensino médio, 187 o superior incompleto e 295 o superior completo. Esses dados fundamentaram as ações dos movimentos sociais, pois era urgente lidar com tamanha desigualdade social. A criação do Pronera, em 1998, teve como um dos propósitos modificar essa realidade escolar.

Na I Pesquisa Nacional da Educação na Reforma Agrária (Pnera), realizada em 2004, foi identificado, entre outras características, que 76\% dos assentados com idade entre 15 a 17 anos estavam estudando, sendo que $17 \%$ deles estavam no ensino médio. Dos que estavam fora da escola, na idade de 15 a 17 anos, 48,1\% estudaram de primeira a quarta série. Dentre os que tinham 18 anos ou mais e estavam fora da escola, 45\% estudaram da primeira à quarta série e 14\% nunca havia frequentado a escola. Ficou registrado que o Brasil tinha 987.890 estudantes em assentamentos, matriculados em 8.679 escolas de 1.651 municípios. A pesquisa foi realizada em 5.595 assentamentos. Constatou-se 524.868 famílias e 2,5 milhões de pessoas. A Pnera identificou algumas prioridades educacionais do país, dentre as quais destacamos as que ocuparam os cinco primeiros lugares: 1) construir, ampliar e/ou melhorar o prédio/as instalações físicas da escola (38,3\%); 2) Ampliar/criar níveis/modalidades de ensino (20,7\%); aumentar vagas nos níveis de ensino existentes $(9,1 \%) ; 4)$ valorizar a cultura, ensinar coisas úteis e dentro do modo de vida do campo (5,7\%); 5) oferecer/melhorar a qualidade do transporte escolar (5,2\%). Nota-se que são necessidades, transformadas em prioridades, históricas da sociedade brasileira. Essas desigualdades atingem crianças, jovens e adultos indígenas de forma semelhante, a exemplo do que ocorre com o acesso ao ensino médio: de cada dezesseis crianças do ensino fundamental, uma chega ao ensino médio.

Em síntese, pode-se se afirmar que as principais conquistas com vistas à superação das desigualdades educacionais no campo, na década de 1990, foram: a reunião de diversos movimentos e organizações populares no fortalecimento da luta pelo reconhecimento dos povos do campo e pela efetivação de políticas educacionais; a realização de conferências estaduais e nacionais dos povos do campo para o debate da educação, portanto, a consolidação de uma frente política. Também, configura-se como conquista o conjunto de experiências educativas em parcerias com as universidades, a exemplo dos projetos vinculados ao Pronera e da produção de coletâneas pedagógicas, ao lado da vasta produção bibliográfica e pedagógica do Setor de Educação do MST. As lutas sindicais por educação para todos também teve impacto no momento de definir artigos na LDB e nas diretrizes operacionais da educação do campo, publicadas em 2002, haja vista a ênfase e lutas na efetivação da educação para todos. As diretrizes operacionais da educação básica para as escolas do campo, de 2002, vieram a ser o documento pioneiro no reconhecimento normativo e legal da educação do campo. 


\section{De 2002 a 2012: as conquistas, os embates judiciais e as lutas ne- cessárias à educação do campo}

Um panorama geral das conquistas efetivadas nos últimos dez anos da educação requer a menção a cinco frentes: espaços públicos de luta e divulgação das experiências da educação do campo; inserção na agenda política e normativa; realização de programas governamentais; produção acadêmico-científica de natureza coletiva; e embates judiciais.

A primeira frente é a da organização dos espaços públicos, como a II Conferência Nacional por uma Educação do Campo (2004). Essa Conferência fortaleceu a concepção e as frentes de luta da educação do campo postas na I Conferência de 1998, ampliou as reflexões que estavam centradas na educação básica e deu ênfase à educação superior e pós-graduação. Os encontros de pesquisadores e participantes dos movimentos sociais do campo, nos Seminários Nacionais da Educação, geraram espaços públicos de debate das experiências político-pedagógicas em desenvolvimento no Brasil.

Na esfera estadual, os fóruns, seminários, simpósios e encontros de educação têm sido organizados. São espaços para debate da realidade escolar, enfrentamentos políticos e proposição de políticas educacionais. Eles reúnem povos do campo, professores, gestores e estudantes. É lugar de aprendizagem político-pedagógica para intervenção em práticas escolares e na gestão educacional local.

No âmbito municipal há muito por fazer, pois os governos têm pouco conhecimento sobre a educação do campo. As parcerias entre universidades, movimentos e escolas públicas, como as que são possibilitadas pelo Observatório da Educação (Capes), despertam a atenção dos professores, gestores e secretários municipais de Educação e, portanto, fazem a diferença ao possibilitarem o desenvolvimento de experiências pedagógicas e debates em torno da realidade educacional local. São construídos grupos de estudos dos textos da educação do campo, são feitos levantamentos da realidade escolar e estudo dos planos municipais de educação, do projeto político-pedagógico, entre outros. Contudo, essas são iniciativas incipientes que precisam de maior impulso em todo o interior do país.

A segunda frente revela a inserção da educação do campo na agenda política e normativa, que tem sido efetivada por meio das manifestações sociais, cartas e declarações elaboradas ao final de cada conferência, seminário e encontro nacional. Em todas elas aparece uma lista de prioridades, todas relacionadas à superação da desigualdade no que tange à formação escolar, as precariedades das instituições escolares e do transporte, a formação deficiente de professores. Os estados têm criado comitês e fóruns estaduais da educação do campo que articulam a sociedade civil à sociedade política. 
As Resoluções do Conselho Nacional de Educação de 2002 e 2008 e o Decreto Presidencial n. 7.352, de 2010, constituem importantes conquistas da educação do campo no âmbito do poder político e da legislação educacional. Esses documentos trazem dispositivos que esclarecem sobre a identidade dos povos do campo, identidade da escola do campo, acesso de pessoas com deficiência à escola, entre outros; norteiam a política da educação do campo e do Pronera. Ao lado desses documentos legais, encontram-se as Diretrizes Curriculares da Educação do Campo de vários estados brasileiros, organizadas a partir do trabalho de equipes multidisciplinares, em sua maioria com pesquisadores com conhecimento ou vínculo direto com movimentos e povos do campo.

A terceira frente é constituída pelos arranjos governamentais construídos a partir das parcerias com as universidades e movimentos sociais, cujo principal exemplo é o Pronera. Ele possibilitou a escolarização de 450 mil jovens e adultos no Brasil, desde a sua criação em 1998. Foram 99.531 pessoas concluintes na modalidade de educação de jovens e adultos (EJA), no período de 1998 a 2002; 299.277 nos anos de 2003 a 2010; 1.874 concluintes do ensino médio e superior entre 1998 e 2002; 46.891 para o período de 2003 a 2010; 461 concluintes da especialização no período de 2003 a 2010. Entre 1998 e 2002, foram envolvidas 45 universidades e, entre 2003 e 2010, foram 65 instituições públicas gratuitas ou sem fins lucrativos (MDA, 2011).

Esse programa contribui para a inserção dos jovens em processos educativos críticos, jovens estes que já começam a ingressar como profissionais na educação superior e a colaborar em outras frentes de lutas. Por meio do Programa, foram criados cursos superiores de Pedagogia, Administração, Direito, Agronomia, Medicina Veterinária, Geografia, entre outros. Esse fato tem motivado a elite conservadora e os profissionais do Direito que lutam pela igualdade formal a proporem ações civis públicas que questionam a legalidade desses cursos, bem como os princípios da isonomia e proporcionalidade.

Outro arranjo é o Programa de Apoio à Formação Superior em Licenciatura em Educação do Campo (Procampo), que foi criado em 2008, primeiro edital de 2009, pelo Ministério da Educação, vinculado à Secretaria de Educação Continuada, Alfabetização, Diversidade e Inclusão (Secadi). O objetivo é enfrentar as desigualdades educacionais no que tange à formação dos professores do campo, valorizando políticas específicas de formação, como é o caso da licenciatura em Educação do Campo. Em 2010, eram 56 turmas de licenciatura em formação, com 1.618 alunos matriculados e um total de 3.358 vagas (incluindo as turmas que teriam início ou reedição).

Em março de 2012 foi lançado o Programa Nacional de Educação do Campo (Pronacampo). Estava inserido na Medida Provisória n. 562/2012, que foi transformada no Projeto de Lei n. 12.695/2012, sancionada pelo presidente em 25 de julho 
de 2012. Com a aprovação da Lei, os objetivos desse programa poderão ser materializados. Dentre os seus objetivos destacam-se: possibilitar ações voltadas ao atendimento das escolas do campo e quilombolas, levando em conta que são cerca de 76 mil escolas, com 6,2 milhões de matrículas e 342 mil professores, em quatro frentes: gestão e práticas pedagógicas; formação de professores; educação de jovens e adultos; educação profissional e tecnológica (MEC, 2012).

A quarta frente é a da produção acadêmico-científica de natureza coletiva. Teve início nos anos de 1990 com as produções do MST e, a partir da constituição da educação do campo, ela está materializada em diversas publicações, tais como a coleção "Por uma Educação Básica do Campo". Nos últimos anos essa produção é intensificada a partir das universidades, em função das inúmeras parcerias com movimentos e organizações populares. São dezenas de obras coletivas dos pesquisadores que trabalham com a prática e concepção da educação, que versam sobre formação de professores, classes multisseriadas, experiências e concepção da educação do campo, residência agrária, histórias das articulações estaduais e nacional, entre outros temas.

Por fim, a quinta frente é a dos embates judiciais contraditórios, mas que fortalecem, porém, a efetivação dos direitos sociais. Os princípios constitucionais da legalidade, isonomia e proporcionalidade são convocados por procuradores do Ministério Público Federal para contestar a existência dos cursos para beneficiários da reforma agrária. Com visão oposta à dos procuradores, existem juízes, como os dos Estados de Goiás e Sergipe, que consideram que esses cursos superiores vinculam-se a uma questão social. Esses juízes afirmam que tais cursos tendem a contribuir para a viabilidade dos assentamentos de reforma agrária e, com isso, para a superação das injustiças sociais históricas. Salientam, ainda, que é preciso tratar desigualmente aqueles que se encontram em situação de desigualdade na sociedade. As batalhas judiciais revelam dois lados na análise de única questão: há os que são favoráveis às políticas afirmativas e aqueles que, em nome da igualdade formal, as condenam. As ações civis públicas existentes desde 2004 demonstram a face injusta da sociedade.

Telles (2006), aos discutir direitos sociais, menciona que:

Quando os trabalhadores rurais sem-terra fazem as ocupações de terra, instauram um conflito que é mais do que o confronto de interesses, pois abrem a polêmica - e o dissenso - sobre os modos como se entende ou pode se entender o princípio da propriedade privada e seus critérios de legitimidade (...). Quando o movimento negro reivindica tratamento igual e protesta (...) contra o racismo (...) abre a polêmica sobre o que se entende ou pode se entender sobre o princípio da igualdade perante a lei, sobre as questões e temas que devem ser levados em conta na deliberação política (...). Quando as populações indígenas reivindicam a demarcação de suas terras, colocam em pauta 
os modos como se entende ou pode se entender os princípios constitucionais que garantem os direitos indígenas, mas também abrem o debate sobre a validade de outros universos culturais (...).

Poderíamos continuar as reflexões da autora perguntando sobre a educação do campo. Certamente, no mínimo, duas interpretações ficam explícitas: uma está vinculada ao Brasil moderno e com ampla produtividade, assentada no discurso da legalidade e da igualdade. Outra é a do Brasil que busca superar a desigualdade e construir mecanismos de atendimento às lutas e propostas dos trabalhadores organizados.

\section{Considerações finais}

A educação do campo originou-se com o intuito de interrogar os condicionantes estruturais históricos da sociedade brasileira, entre eles a desigualdade educacional, os processos econômicos e políticos excludentes e a prática tecnocrática e patrimonialista de elaboração de políticas públicas.

Foram as práticas educativas coletivas das reuniões e estudos locais e conjunturais nos movimentos sociais que desencadearam as manifestações e os espaços públicos conhecidos como conferências, seminários, encontros e simpósios da educação do campo. Esses espaços públicos que integram a sociedade civil e a sociedade política dão forma a uma esfera pública de negociações, tensões, embates e projetos em parceria. Trata-se de um corpo complexo, do ponto de vista da identidade política dos participantes, que busca a superação das contradições históricas, verificadas na distância do Estado/poder com a sociedade; na distância dos governos com os movimentos sociais e na ideologia que, em nome da igualdade formal e positivista, impede os avanços da reforma agrária e a efetividade dos direitos sociais.

A concepção e a prática da educação do campo geraram experiências coletivas inéditas na sociedade brasileira, a exemplo dos cursos superiores para os beneficiários da reforma agrária e da agricultura familiar. A criação desses cursos tem instigado a sociedade civil, desde a ideologia capitalista, e o Ministério Público Federal, em alguns casos, a inserir no Poder Judiciário a discussão sobre igualdade e direito social à educação, no contexto da reforma agrária. Não é possível avaliar os impactos, porém é possível dizer que instâncias do Poder Judiciário têm sido favoráveis à efetivação do direito à educação, em nome da igualdade fática e, portanto, da superação da desigualdade social, com intuito de potencializar as formas de superação da desigualdade social, em especial nos assentamentos.

Conclui-se que a educação do campo tem gerado impactos de diferentes naturezas. A principal delas está na prática de construir a política educacional. Reiteram-se as lutas por políticas educacionais, muitas iniciadas pelos povos indígenas. Aos 
poucos, a realidade dos povos do campo, das escolas e os interesses coletivos são considerados na elaboração de políticas educacionais direcionadas à transformação da própria realidade. Essa prática de construção coletiva de políticas exige que, no interior do Estado e dos governos, existam pessoas e coletivos com conhecimento da realidade, das ideologias em jogo, dos fatores estruturais que dificultam o avanço da democracia e a superação das desigualdades no país.

Para encerrar, destaca-se que um dos impactos e desafios das lutas da educação do campo é o reconhecimento da diversidade de trabalhadores do campo brasileiro no momento de elaborar políticas educacionais. Afinal, discutir identidades e culturas tão específicas como a dos indígenas, povos das florestas, ribeirinhos, caiçaras, ilhéus, quilombolas, faxinalenses, assentados, acampados, mulheres camponesas, entre outras, exige esforço pedagógico e político. Corre-se o risco de mascarar as diferenças e diversidades em nome da igualdade. Outros segmentos que têm tido destaque na elaboração das políticas públicas são: jovens e idosos do campo e pessoas com necessidades especiais. Pouco ou nada era dito ou investigado desses sujeitos trabalhadores nas pesquisas educacionais até recentemente. Na luta contra a desigualdade educacional, reconhece-se a existência da diversidade e, com ela, a busca da superação das desigualdades sociais mediante a luta e construção de políticas públicas voltadas à agricultura familiar e à reforma agrária.

\section{Nota}

1. Ação Civil Pública proposta pelo MPF da Regional de Pelotas e da Regional de Goiás (Goiás Velho), contra os cursos de Medicina Veterinária da Universidade Federal de Pelotas (Ufpel) e de Direito da Universidade Federal de Goiás (UFG), respectivamente. E a ação civil pública proposta pela Associação dos Engenheiros Agrônomos do Estado de Sergipe, contra o curso superior de Agronomia da Universidade Federal do Sergipe (UFS).

\section{Referências}

ARROYO, M.G. Diversidade. In: CALDART, R.S. et al. (Org.). Dicionário da educação do campo. Rio de Janeiro: Escola Politécnica de Saúde Joaquim Venâncio; São Paulo: Expressão Popular, 2012. p. 229-236.

BRASIL. Constituição (1988). Constituição da República Federativa do Brasil. São Paulo: Saraiva, 2010.

BRASIL. Decreto n. 7.352, de 4 de novembro de 2010. Dispõe sobre a política de educação do campo e o Programa Nacional de Educação na Reforma Agrária - Pronera. Diário Oficial da União, Brasília, DF, 5 nov. 2010. 
BRASIL. Lei n. 11.326, de 24 de julho de 2006. Estabelece as diretrizes para a formulação de política nacional de agricultura familiar e empreendimentos familiares rurais. Diário Oficial da União, Brasília, DF, 25 jul. 2006. Disponível em: <http://www.planalto.gov.br/ccvil_03/_Ato2004-2006/2006/Lei/L11326.htm>. Acesso em: 20 abr. 2012.

BRASIL. Lei n. 11.947, de 16 de junho de 2009. Dispõe sobre o atendimento da alimentação escolar e do Programa Dinheiro Direto na Escola aos alunos da educação básica... Diário Oficial da União, Brasília, DF, 17 jun. 2009

BRASIL. Ministério da Educação. Resolução CNE/CEB n.1, de 3 de abril de 2002. Institui Diretrizes Operacionais para a Educação Básica das Escolas do Campo. Diário Oficial da União, Brasília, DF, 9 abr. 2002.

BRASIL. Ministério da Educação. Resolução CNE/CEB n. 2, de 28 de abril de 2008. Estabelece diretrizes complementares, normas e princípios para o desenvolvimento de políticas públicas de atendimento da Educação Básica do Campo. Diário Oficial da União, Brasília, DF, 29 abr. 2008.

BRASIL. Ministério da Educação. Instituto Nacional de Estudos e Pesquisas Educacionais (Inep). Pesquisa Nacional de Educação na Reforma Agrária. Brasília, DF: MEC/Inep, 2005. 158f. Disponível em <http://www.lepel.ufba.br/PNERA.pdf >. Acesso em: 20 abr. 2012.

BRASIL. Ministério da Educação. Instituto Nacional de Estudos e Pesquisas Educacionais (Inep). Panorama da educação do campo. Brasília, DF: MEC/Inep, 2007.

BRASIL. Ministério da Educação. Pronacampo: Programa implementará educação do campo e atenderá 76 mil escolas. Brasília, DF: MEC, 2012. Notícia publicada em 20/03/2012. Disponível em: <http://portal.mec.gov.br/index.php?option=com_ content\&view=article\&id=17608>. Acesso em: 24 abr. 2012.

BRASIL. Ministério do Desenvolvimento Agrário. Educação no campo: Pronera já beneficiou 450 mil jovens e adultos do campo. Notícia publicada em 08/02/2011. Disponível em: <http://www.mda.gov.br/portal/noticias/item?item_id=6852707>. Acesso em: 20 abr. 2012.

CALDART, R.S. Educação em movimento: formação de educadoras e educadores do MST. Petrópolis: Vozes, 1997.

INSTITUTO DE PESQUISA ECONOMICA APLICADA (IPEA). Pobreza, desigualdade e políticaspúblicas;comunicadosdaPresidêncian.38.Brasília,DF:Ipea,2010.Disponívelem $<$ http://www.ipea.gov.br/sites/000/2/comunicado_presidencia/100112Comunicado38. pdf> Acesso em: 28 abr. 2012.

MARSIGLIA, A.C.G.; MARTINS, L.M. Programa Escola Ativa: análise crítica. In: 
BARBOSA, M. V.; MENDONÇA, S.G.L. (Org.). Ensino e aprendizagem como processos humanizadores: propostas da teoria histórico-cultural para a educação básica: coletânea de textos da 9a Jornada do Núcleo de Ensino de Marília. Marília: Oficina Universitária Unesp, 2010. 14p.

MOLINA, M.C. A constitucionalidade e a justiciabilidade do direito à educação dos povos do campo. In: SANTOS, C.A. (Org.). Por uma educação do campo: campo políticas públicas - educação. Brasília, DF: MDA; Incra, 2008. p. 19-31.

MOVIMENTO DOS TRABALHADORES RURAIS SEM TERRA (MST). Dossiê MST Escola: documentos e estudos 1990-2001. [S.1.]: Iterra/RS; Seed/PR, 2005.

MOVIMENTO DOS TRABALHADORES RURAIS SEM TERRA (MST). Educadores lançam manifesto contra o fechamento de escolas no meio rural. Notícia publicada em 14/10/2011. Disponível em: <http://www.mst.org.br/node/12562>. Acesso em: 4 abr. 2012.

MUNARIM, A. Movimento nacional de educação do campo: uma trajetória em construção. 2008. 17f. Disponível em: <http://www.anped.org.br/reunioes/31ra/1trabalho/GT034244--Int.pdf>. Acesso em: 27 jul. 2012.

MUNARIM, A. Educação do campo e políticas públicas: controvérsias teóricas e políticas. In: MUNARIM, A. et al. Educação do campo: políticas públicas, territorialidades e práticas pedagógicas. Florianópolis: Insular, 2011. p. 21-38.

NÚCLEO DE ESTUDOS, PESQUISAS E PROJETOS DA REFORMA AGRÁRIA (NERA). Atlas da questão agrária brasileira. Disponível em: <http://www2.fct.unesp. br/nera/atlas/estrutura_fundiaria.htm>. Acesso em: 19 maio 2012.

I CENSO DA REFORMA AGRÁRIA DO BRASIL; relatório final. Brasília, DF: Data UnB, 1997.

ROUSSEAU, J.J. Rousseau. São Paulo: Nova Cultural, 1997. v. 2. (Os pensadores)

SOUZA, M.A. Educação do campo: propostas e práticas pedagógicas do MST. Petrópolis: Vozes, 2006.

SOUZA, M.A. Educação e movimentos sociais do campo: a produção do conhecimento no período de 1987 a 2007. Curitiba: UFPR, 2010.

SOUZA, M.A. Análise crítica das decisões judiciais sobre os cursos superiores para beneficiários da reforma agrária. 2012. 112f. Trabalho de Conclusão de Curso (Direito) Universidade Tuiuti do Paraná, Curitiba.

STEFANIAK, J.N. Propriedade e função social: perspectivas do ordenamento jurídico e do MST. Ponta Grossa: UEPG, 2003. 
TELLES, V. S. Direitos sociais: afinal do que se trata? Belo Horizonte: UFMG, 2006.

VEIGA, J.E. Cidades imaginárias: o Brasil é menos urbano do que se calcula. 2. ed. Campinas: Autores Associados, 2003.

VENDRAMINI, C.R. Ocupar, resistir e produzir - MST: uma proposta pedagógica. 1992. 184p. Dissertação (Mestrado em Educação) - Universidade Federal de São Carlos, São Carlos.

VERDE, V.V. Territórios, ruralidade e desenvolvimento. Curitiba: Instituto Paranaense de Desenvolvimento Econômico e Social (Ipardes), 2004. 35f.

WANDERLEY, L.E.W. A questão social no contexto da globalização: o caso latinoamericano e o caribenho. In: CASTEL, R.; WANDERLEY, L.E.W; BELFIORE-WANDERLEY, M. Desigualdade e a questão social. 2. ed. São Paulo: Educ, 2000. p. 51-161.

Recebido em 7 de junho de 2012.

Aprovado em 14 de agosto de 2012. 